\title{
Testemunhos durante a pandemia: reflexões psicanalíticas sobre trauma, Estado, economia e morte
}

\section{Testimonies during the pandemic: psychoanalytic reflections on trauma, State, economy and death}

\author{
Luiz Alberto de Souza Junior ${ }^{a}$ \\ (D) https://orcid.org/0000-0001-5221-1406 \\ E-mail: luiz.albertoळsempreceub.com \\ Guilherme Freitas Henderson ${ }^{a}$ \\ (iD) https://orcid.org/0000-0002-2837-7569 \\ E-mail: guilherme.hendersonळceub.edu.br \\ ${ }^{a}$ Centro Universitário de Brasília (UniCEUB). Faculdade de \\ Ciências da Educação e Saúde. Departamento de Psicologia. \\ Brasília, DF, Brasil.
}

\section{Correspondência}

\section{Resumo}

Este trabalho propõe-se a refletir sobre a experiência do sujeito perante a pandemia de covid-19 por meio de uma perspectiva psicanalítica. O material analisado discursivamente foi constituído por testemunhos de estudantes de graduação em psicologia publicados em um espaço virtual durante o período de distanciamento social. Os processos de subjetivação destacados em nossa análise foram discutidos em quatro núcleos temáticos: enfrentar o potencial traumático: poder testemunhar a queda do Outro; o (des)amparo dos sujeitos por parte do Estado: a potencialização do sofrimento psíquico; o imperativo superegoico da produção capitalista e os vestígios produtivos da improdutividade; (im)possibilidades do luto: transformações da nossa atitude diante da morte. Ao fim, buscamos evidenciar criticamente o aspecto destrutivo e autoritário da gestão estatal dos afetos sobre os sujeitos e a potência transformativa (analítica e política) das experiências da improdutividade, da indeterminação e do desamparo.

Palavras-chave: Pandemia; Covid-19; Coronavírus; Psicanálise; Teoria Social. 
This study aims to reflect on the subject's experience in the face of the covid-19 pandemic by a psychoanalytic perspective. The material analyzed discursively was constituted by testimonies of undergraduate psychology students published in a virtual space during the period of social distance. The subjectivation processes emphasized in our analysis were discussed in four thematic groups: facing the traumatic potential: being able to witness the fall of the Other; the (un)protection of the subjects by the State: the potentiation of psychological suffering; the superegoic imperative of capitalist production and the productive traces of unproductivity, and (im possibilities of mourning: changes in our attitude towards death. Finally, we seek to critically evidence the destructive and authoritarian aspect of the state management of affections on subjects and the transformative power (analytical and political) of the experiences of unproductivity, indeterminacy and helplessness.

Keywords: Pandemics; Covid-19; Coronavirus; Psychoanalysis; Social Theory.
O tema pandemia tornou-se incontornável na atualidade. Predominante na mídia, o assunto ocupa amplamente o meio acadêmico nas mais diversas áreas, de discussões epidemiológicas a projeções econômicas, considerações político-sociológicas e psicológicas. Por um lado, há a presença de discursos que buscam contornar o mal-estar vivenciado pelos sujeitos lhes fornecendo um saber que pretende ser capaz de amparálos; por outro, discursos que buscam produzir, gerir e controlar os afetos do medo, terror e a insegurança.

Além do distanciamento físico exigido nesse contexto de incertezas, sabemos pela experiência psicanalítica que, adjacente a tais discursos, é possível surgir processos de individualização do sofrimento, os quais negam sua dimensão coletiva, social e histórica, além de processos de desrealização da singularidade da experiência vivida pelos sujeitos, o seu não reconhecimento pelo outro (Appoa, 2018). Entre os sujeitos, cada vez que se fala sobre a covid-19, se presentifica um sentimento de angústia comumente seguida por um silenciamento recíproco. Impossibilitados de articular o mal-estar que os habita, efeito da situação atual mas também da sua própria história, os sujeitos assistem como espectadores de seu próprio sofrimento a um crescente aumento dos níveis de ansiedade, compulsões, perturbações no sono e outros sintomas.

A psicanálise, ancorada em sua práxis ética, responde à crise pandêmica, oferecendo reflexões e intervenções próprias a sua teoria e a sua clínica que buscam, sobretudo, criar dispositivos de escuta e elaboração do sofrimento que incluam o sujeito do inconsciente mais além de discursos exteriores que o desimplicam desse processo. Inserindo-se nesse debate e reconhecendo sua precocidade, este trabalho visa oferecer reflexões sobre o processo de subjetivação da situação de distanciamento social por ocasião da pandemia de covid-19.

Trata-se de estudo um psicanalítico qualitativo cujo objeto foi obter testemunhos feitos por alunos universitários em um diário virtual sob formato de blog criado por um professor no dia 20 de março de 2020. O blog estava organizado em três sessões: "Envie seu Testemunho", "Diário" e "Nossa Proposta". Trabalhamos com as postagens realizadas na sessão 
“Diário", entre março e abril de 2020. Nesse período, os alunos realizaram 251 postagens anônimas. Na sessão "Nossa Proposta", o autor do blog convida os alunos a postar um diário de testemunhos a fim de criar um espaço coletivo-íntimo de elaboração da experiência de distanciamento social. Essa escrita não era compulsória. $O$ diário era aberto a relatos de qualquer natureza, e os estudantes eram estimulados a narrarem livremente suas vivências, seus pensamentos, afetos, desejos, angústias ou qualquer outra coisa que lhes parecesse relevante nesse período.

Selecionamos todas as postagens que foram analisadas por meio da análise de conteúdo (Bardin, 1977), por meio da qual foi realizado um levantamento qualitativo de quatro núcleos de significado (trauma, estado, economia e morte) e suas classificações foram organizadas em categorias temáticas que puderam ser construídas e discutidas a partir de algumas chaves de leitura fornecidas pela teoria psicanalítica e pela teoria social. Cabe ressaltar que a produção deste texto, a seleção e a escuta sensível do material também ocorreram no contexto de distanciamento social, estando os próprios autores nele implicados. Dessa forma, elementos subjetivos inconscientes dos próprios pesquisadores, como sujeitos, fazem parte dessa análise.

Os testemunhos publicados pelos estudantes nesse diário virtual sinalizam de maneira sensível a multiplicidade de afetos que lhes atravessam nessa experiência (o medo, a esperança ou o desamparo) e os diversos sintomas que surgem de súbito e de maneira crescente (a ansiedade, o pânico e a insônia), implicadas as manifestações do inconsciente que se apresentam nesse contexto, buscando inscrever seu saber singular (as fantasias, os sonhos, os pesadelos e os atos falhos). Revelam ainda o quanto os sujeitos, perante uma situação insólita de pandemia, precisam enfrentar não apenas os perigos objetivos do contágio do vírus, mas uma série de discursos que potencializam o seu sofrimento e o destituem como sujeitos.

Foram observados os aspectos éticos estabelecidos na Resolução no 510/2016, do Conselho Nacional de Saúde. Esclarecemos que essa pesquisa é caracterizada como risco mínimo, os materiais utilizados são de acesso público, estão disponíveis on-line e protegidos pelo anonimato e, desta forma, não foi possível identificar seus autores. Além disso, optamos por não identificar, com os pseudônimos utilizados pelos autores das postagens, os fragmentos utilizados no decorrer da nossa análise.

Nesse sentido nosso esforço qualitativo é extrair de tais testemunhos o que o sujeito afetado pela experiência da pandemia tem a dizer. Eticamente, sabemos que esse resgate "depende de haver lugar, espaço, desejo (sobretudo, desejo do analista) sustentados em dispositivos capazes de garantir o livre curso da palavra, para que o ocorrido e seus efeitos venham à luz, suas consequências traumáticas sejam reconhecidas e inscritas na linguagem, no coletivo" (Ramos, 2018, p. 15). Entendemos que o processo de escrita dos testemunhos, o compartilhamento entre os pares e, agora, a análise dos relatos e sua produção teórica podem compor diversas modalidades de inscrição e reconhecimento dessa experiência. O pressuposto ético que nos orienta e inspira este trabalho é compartilhado pela ética que orienta a Clínica do Testemunho (Appoa, 2018), uma tentativa de produzir torções nos discursos que (des)organizam o laço social, a fim de possibilitar o início da construção de uma memória coletiva que permita uma elaboração da experiência e resista às estruturas dominantes e abusivas de poder.

\section{Enfrentar o potencial traumático: poder testemunhar a queda do Outro}

“Trauma” se tornou uma palavra em voga nestes dias de pandemia. Noção tenazmente explorada na psicanálise desde sua origem, quando Freud ainda se debatia com a natureza real ou fantasmática dos traumas de abusos infantis narrados por suas pacientes histéricas. Freud (1990) parte de um raciocínio quantitativo em que trauma é um excesso de energia psíquica que, impossibilitada de circular, se coagula em forma de sintoma (Freud, 1996a). A partir de 1920, o psicanalista pensa o trauma a partir de sua relação com a repetição: o traumático produz a compulsão à repetição (Freud, 1996b), uma tentativa do sujeito de reviver o trauma em busca de uma redução de sua energia psíquica e sua simbolização. Aquilo que não pode ser recordado no nível simbólico retorna como ato repetitivo. A concepção de repetição de situações e 
sentimentos desprazerosos demonstra outro modo de funcionamento psíquico para além do princípio do prazer, nascendo, assim, a pulsão de morte, um incessante esforço de retornar ao estado anterior das coisas, esforço nostálgico esse bastante presente nos atuais dias pandêmicos.

Chama a atenção de Freud, em 1920, no texto Mais além do princípio do prazer que, nos sonhos traumáticos e repetitivos de sujeitos que experienciaram a guerra, houvesse um retorno incessante à situação do horror, apesar de todo desprazer e sofrimento contidos ali. De maneira homóloga, se pensa a clássica cena do jogo de carretel - o sobrinho que dizia fort, ao jogar o carretel de linha e da ao puxar o carretel - como uma tentativa de recuperar, agora de maneira ativa, aquilo que havia sofrido passivamente: o sentimento de desamparo efeito da partida da mãe.

A repetição presente tanto no sonho traumático quanto na brincadeira da criança busca inscrever no campo simbólico uma experiência não simbolizada. Para esse processo, o sujeito investe uma boa parte da sua energia psíquica, o que poderá promover um empobrecimento de "todos os outros sistemas psíquicos, de sorte que o resultado é uma extensa paralisia ou rebaixamento de qualquer outra operação psíquica” (Freud, 1996b, p. 30). O efeito desse intenso trabalho psíquico pode se manifestar nas queixas de cansaço, estresse, ansiedade e depressão profusas no cenário de pandemia.

A compulsão à repetição revela, então, que o sujeito "traz em si uma história impossível de ser simbolizada e, portanto, transmitida” (Betts, 2018, p. 118). Impossibilidade ilustrada na origem grega da palavra, traûma: ferida, dano ou avaria, que sustenta a corruptela lacaniana de troumatismo (Lacan, 2018) em que trou, buraco em francês, não se refere a um ferimento na realidade objetiva, mas no simbólico, se refere a um buraco na produção de sentido. Na tentativa de ilustrar esse impossível recorremos ao sonho traumático relatado por Primo Levi:

Aqui está minha irmã, e algum amigo (qual?), e muitas outras pessoas. Todos me escutam, enquanto conto do apito em três notas, da cama dura, do vizinho que gostaria de empurrar para o lado, mas tenho medo de acordá-la porque é mais forte que eu. Conto também a história da nossa fome, e do controle dos piolhos, e do Kapo que me deu um soco no nariz e logo mandou que me lavasse porque sangrava. É uma felicidade interna, física, inefável, estar em minha casa, entre pessoas amigas, e ter tanta coisa para contar, mas bem me apercebo de que eles não me escutam. Parecem indiferentes; falam entre si de outras coisas, como se eu não estivesse. Minha irmã olha para mim, levanta, vai embora em silêncio. (Levi, 1988, p. 6o)

Destacamos que a angústia nesse sonho não se relaciona objetivamente com a experiência inumana vivenciada no campo de concentração, o que gera o terror e, em seguida, o despertar do sonho está na cena em que o sujeito conta sobre o horror vivido e o fato de não encontrar a escuta do Outro. Vemos que o traumático testemunhado nessa manifestação do inconsciente não é da ordem dos fatos, mas do fracasso do processo simbolização, de não se conseguir fazer disso uma experiência compartilhável.

Não nos parece por acaso que os problemas do sono despontam como os primeiros que afetam os sujeitos no período da quarentena. A insônia, os pesadelos recorrentes, o sono desregulado, não satisfatório: o primeiro ponto que percebi durante esse tempo éque o meu sono não está sendo como era antes. Demoro para conseguir dormir, tenho sonhos estranhos e acordo algumas vezes durante a noite. Provavelmente por conta das preocupações; Hoje fui acordada com o meu paime perguntando se eu tive algum pesadelo durante a noite, pois eu comecei a gritar. Eu não me lembro de nada disso. Por outro lado, o dormir surge também como um lugar psíquico no qual podemos escapar do "pesadelo" da realidade: Sinto como se todos os dias fossem cinzentos, tenho dificuldade em saber em que dia estamos e quando acordo desnorteado tenho vontade de simplesmente continuar dormindo.

A partir do sonho de angústia paradigmático exposto acima, podemos analisar um dos testemunhos do diário, uma narrativa em que, primeiro, se apresenta um ato falho, em seguida, o relato de um sonho, ambos ocorrem durante o período de distanciamento social:

Hoje estava conversando com meu marido sobre filmes, procurando um filme na Netflix para assistir, e cometi um ato falho, disse a ele que nunca assisti o filme "quem quer ser MEU milionário". Caí numa 
gargalhada. Me vi do avesso. Instantaneamente pensei que se fôssemos ricos nossa quarentena estaria sendo muito diferente. Tive um sonho nessa mesma noite. Meus pais haviam comprado uma mansão e nos convidando para morar com eles. Na primeira noite um ser maligno ronda a casa, meu pai não acredita nos meus avisos. Digo a ele que isso não era coisa da minha cabeça.

$\mathrm{Na}$ fachada desse sonho, notamos a presença de afetos como a esperança, o medo, o sentimento de estar à mercê e de uma estrutura de negação ("isso é coisa da sua cabeça”) comuns às vivências no período da pandemia. Do material apresentado, podemos tomar o sonho, que ocorre na mesma noite, como uma resposta àquilo que se apresenta no ato falho como questão. Quem quer ser meu milionário? O sonho responde: meus pais. Mas, ao mesmo tempo, aponta para o mais além dessa fantasia: de que adianta ter "seu milionário", ser rico, ter agora uma mansão, se isso não garante proteção nenhuma? Tendo em vista que a denegação do pai de achar que isso "é coisa da sua cabeça" é aquilo que de fato te coloca em perigo, e esta, pelo visto, não se resolve com milhões no bolso.

Nesse sentido, tal como o sonho relatado por Primo Levi, poderíamos dizer que aquilo que parece mais assustador nesse sonho não é bem o ser maligno que ronda a casa (figura bem representativa do vírus da pandemia), mas o fracasso da instância paterna em reconhecer esse ser e a preocupação no sonhador em não se fazer crer. 0 saber que se revela na interpretação desse sonho não aponta justamente para essa verdade que precisa ser atravessada pelo sonhador? A verdade de que, apesar de tentar responder à sua demanda de amparo fantasiando a figura do pai que o protege, essa esperança de amparo se mostra caduca e até mesmo perigosa no contexto do sonho. A única saída é ele enfrentar esse mal sozinho, enfrentar por meio do desamparo.

\section{o (des)amparo dos sujeitos por parte do Estado: a potencialização do sofrimento psíquico}

Se o simples ato de narrar sua história já demanda bastante à economia psíquica, a situação ganha outra dimensão quando o Outro enquanto Estado coloca certos interditos. Estado ao qual os cidadãos endereçam um desejo de amparo, apoio e reconhecimento, sobretudo em momentos de crise, independente da veracidade da informação, como ilustra a seguinte entrada no diário: ontem descobri que o Reino Unido tem o Ministério da Solidão. Olha que coisa! Um ministro para cuidar da solidão das pessoas... Como precisamos desse cuidado.

Contudo, testemunhos revelam uma situação inversa no Brasil na qual o Estado se ausenta ou mesmo é partícipe do sentimento de insegurança: depois daquele discurso do presidente há alguns dias, me travei... Parece que ouvir aquelas palavras daquele ser humano me intensificou o medo. A questão, portanto, ganha novos e graves contornos quando o trauma é perpetrado pela figura que supostamente teria como função prover e proteger o sujeito, figuras paternas, maternas e, entrando nessa categoria, o Estado. "O terror, quando praticado pelo Estado, atinge inevitavelmente toda a sociedade. Quando o agente regulador dos vínculos sociais se põe na ilegalidade, é a própria substância normativa da sociedade que se dissipa" (Abrão, 2014, p. 16).

Safatle (2016) argumenta que, hobesianamente, o Estado gerencia a insegurança da população como estratégia para se fazer imprescindível. Trata-se de uma estratégia para se fazer necessário, por meio da qual, ao permitir um nível de terror controlado, ele surja como último bastião da segurança, mostrando toda sua pertinência. Assim, na tese safatliana, a função do Estado de promoção do bem-estar não é absoluta, é antes regulada por seu próprio interesse de autopreservação. O governo que se encontra no poder apenas herda tal lógica de sobrevivência estatal e a administra conforme seus interesses políticos. 0 enfrentamento a pandemia é, portanto, comprometido por essa dinâmica bombeiroincendiário do Estado, em que o bem-estar estatal estará sempre à frente do bem-estar social.

Trata-se de um uso melancólico do poder, isto é, a interiorização por parte do cidadão de que ele é merecedor da angústia, que não há nada possível a ser feito e que o Estado, no formato presente, é a única opção viável. Não é relevante se essa ameaça é ilusória ou mesmo delirante (como a ameaça do objeto intrusivo “o comunista”). Uma vez inculcados 
o temor e o desamparo, o cidadão se volta ao Estado protetor. Nessa perspectiva, não nos parece distante pensar a possibilidade de que certos discursos ideológicos se apropriem das políticas (ou não políticas) de gestão da pandemia, não para gerir os perigos da contaminação em massa, mas parar gerir os afetos que perpetuam o atual status quo político ao custo da fragmentação social e de vidas.

O Estado, ao priorizar sua sobrevivência e não a de sua população, se ausenta de sua função de proteção social e coloca em risco o pacto social. A psicanálise demonstra o risco de tal rompimento, pois o simbólico desautorizado pelo Estado retornará em outros formatos, isto é, o Estado se torna produtor de fraturas simbólicas de potencial traumático. Traumas latentes estes oriundos das (in)ações de uma significativa parte do Estado brasileiro durante a crise, percebidos por muitos como um mal-estar adicional imposto pelo Outro que, ao inverter sua função, amplifica o medo e a insegurança. Nesse sentido, a iminência traumática do nosso atual cenário convoca esferas para além da clínica, toda coletividade, a justiça, a mídia e, sobretudo, convoca o Estado a ocupar uma de suas funções fundamentais.

Os vizinhos aqui só faltam se matar por política. $o$ mundo sangra e os conchavos e achaques políticos não terminam, eis o que nos testemunham. Entendemos que o tecido social rompido, por ser partilhado por todos como suporte aos discursos, precisará ser suturado de forma coletiva. O reconhecimento e a expiação das ações por parte da esfera pública são fundamentais para que se forme uma reparação mais completa e abrangente possível, contudo, como demonstra o trecho citado, essa remissão no presente momento parece estar bastante distante no horizonte político.

Por vezes esse sequestro do registro simbólico, que pode ser operado por algumas figuras do Estado, busca ditar as diretrizes dessa inscrição. Quando discursos minoritários, mas não necessariamente de minorias populacionais, são silenciados, quando há uma disputa de narrativas, percebemos essa manobra em curso. Temos exemplo disso no negacionismo histórico de eventos como o holocausto, a ditadura brasileira e agora a pandemia. Acontecimentos fartamente comprovados e estudados são simplesmente desacreditados, fontes confiáveis e especialistas são preteridos por achismos midiáticos e de internet. A gravidade do vírus, sua letalidade e taxa de disseminação se tornaram foco de uma disputa narrativa, sendo constantemente questionadas por governantes a despeito de todas as evidências científicas e até mesmo diante de eventos ocorridos em outros países. A operação de tomar fatos por fantasias, histeria no dizer de alguns políticos, desordena o registro simbólico do sujeito. Assim, vivências aterrorizantes têm não somente sua possibilidade de inscrição interditada, mas sua própria existência questionada, tal como o sonho de Levi e do testemunho analisado.

O Estado, ao manejar a insegurança dos cidadãos, potencializa o medo do sujeito, o qual fica cindido e pensa em termos de uma falsa escolha: presente ou futuro; saúde ou economia. Assim, exige-se do sujeito que ele constitua seu sintoma em uma única via, a do trabalho, do fortalecimento da economia, reduzindo-o à condição de objeto submetido a um mestre absoluto. Frases proferidas pelo atual presidente da República, como as citadas "isso é apenas uma "gripezinha", "vão morrer mesmo, e daí?", revelam os sujeitos sendo tomados como objetos, em que aquilo que é da ordem do sofrimento, da subjetividade, não importa.

Tais ilegalidades em âmbitos institucionais acabam por tentar desfazer a própria estrutura normativa do laço social e constituir novos traumas pela fratura das instâncias simbólicas. Nesse sentido, estamos lidando com dois desastres ao mesmo tempo: o natural e o simbólico. O vírus é um desastre natural, um evento externo, biologicamente e medicamente explicado. Diferente das imposições advindas da violência de outro humano e das instituições que supostamente lhe serviriam de amparo, estas atingem o campo simbólico, aquele das instâncias em que nos fazemos reconhecer em nosso sofrimento.

\section{O imperativo superegoico da produção capitalista e os vestígios produtivos da improdutividade}

Em tempos de pandemia, a arena de disputa principal no Brasil parece ser a econômica. Em um polo, os que se preocupam com a letalidade atual do vírus, 
em outro, os que fazem projeções econômicas sobre quantas mortes o desemprego causará. Posto em outros termos, há um adiamento do perigo viral presente para um tenebroso cenário do futuro macroeconômico. Morrer de fome por desemprego parece ser mais concreto que morrer pelo vírus. 0 sujeito neoliberal em plena experiência pandêmica segue a se defrontar com os efeitos deletérios imanentes ao capitalismo em sua fase financeira e de serviços. Desemprego, precarização e terceirização do trabalho reificam o sujeito e o forçam a continuar a produzir, ainda que à custa de profundo sofrimento psíquico ou mesmo de uma eventual contaminação. O Estado, mais uma vez, pode manejar a seu favor todas essas questões, não oferecendo um suporte condizente com a situação de exceção causada pelo vírus.

Lustoza (2009) argumenta sobre como capitalismo, enfatizando a acumulação da mais-valia como um movimento sem ponto de basta, deixa o sujeito num estado de insatisfação constante, procurando sempre o próximo e fugaz gozo. Relação produção-gozo que não escapou a Lacan: "O que Marx denuncia na maisvalia é a espoliação do gozo” (Lacan, 1992, p. 76). Esse excesso é ressignificado dentro de uma fantasia neoliberal na qual a mais-valia se coloca no lugar da causa do desejo (Quinet, 2002), portanto, mesmo em tempos de distanciamento social, o imperativo superegoico lacaniano "Goza!" (Lacan, 2005a) continua em pleno funcionamento.

No discurso do Outro como economia capitalista, a função trabalho é que dita as coordenadas do sujeito, situando-o em um lugar no qual é desejado baseado no que produz. Isto gera uma miséria de significantes que, atribuídos ao sujeito, reduzem sua condição à de mero produtor/produto, tornando-se presa fácil para discursos que exaltam seu valor na cadeia produtiva, que reconheçam a, talvez, única função que lhe permitem cumprir na sociedade.

Dessa forma, insistir em produzir comporta em si um elemento traumático sem elaboração, um trauma tão amplo e difuso na sociedade que simplesmente percebê-lo já chega nas bordas do real escapando do simbólico. Como nos lembra Zizek provocativamente em frase a ele atribuída, "é mais fácil imaginar o fim do mundo que imaginar o fim do capitalismo". Até uma sensação subfebril... Me entreguei, não resisti... E deixei o tempo passar, mesmo com a culpa voando ao redor como um verdadeiro Dementador [criaturas da saga Harry Potter que se alimentam de felicidade humanal, testemunhou um estudante que arriscou produzir até os limites da febre.

"Rotina" parece ser a palavra de ordem para continuar a produção: Quando comecei com a nova rotina me senti muito melhor, mais disposta $e$ produtiva. Aqui, o advérbio "melhor" qualifica o sujeito de maneira curiosa, com base em sua produção: sente-se melhor porque é produtiva. Esse uso nos leva a questionar se há de fato uma vivência criativa de saúde ou apenas uma normalização da produção a patamares anteriores. O importante é continuar a produção, que toma estatuto de um endereçamento ao Outro. Temos, assim, uma produtividade que visa atender, não a um desejo inventivo, singular, mas ao desejo instaurado pela ordem neoliberal.

Essa mesma lógica valeria para as demais atividades de suporte, digamos assim, para o tipo de sistema de produção capitalista que vivenciamos, ilustrado na educação, que é entendida empobrecidamente como mera formação e preparação profissional. É patente na atualidade da pandemia a preocupação dos pais com os filhos não serem prejudicados em sua formação ou dos universitários não terem o semestre cancelado. Quão mais trágico, ou melhor, quão mais real seria perder um semestre, um ano que seja, em comparação com perder a vida? Parafraseando Zizek, é mais fácil imaginar os prejuízos de perder um ano letivo que imaginar perder a vida.

Novamente, o diário é copioso em testemunhos com esses questionamentos. Sinto-me pressionada diariamente pela faculdade, há uma quantidade enorme de trabalhos, atividades semanais.; me vejo super atrasada nos trabalhos da faculdade, perdida, angustiada e ansiosa... Ansiedade, algo que eu raramente experimento e essa manhã me vi suando de ansiedade, pensando em trabalhos...; Hoje o dia foimais produtivo, estudei bastante, adiantei muito as leituras porém fico preocupada em como será esse semestre. Por meio dos testemunhos, os alunos conseguem conceber, simbolizar, os prejuízos financeiro-materiais, até psíquicos, de um atraso na formação.

Sinceramente, por um lado eu pensava "Eu mereço descansar e não fazer nada às vezes, amanhã eu faço algo", porém, por outro pensava: "Caramba, eu preciso fazer algo produtivo"; assim como no 
trabalho, onde sempre fui elogiada por ser produtiva e agora não consigo finalizar nada direito; ontem foi um dia tão pouco produtivo, fiquei de cama o dia inteiro... Para analisarmos esses trechos nos parece pertinente o conceito de acting out, que pode ser lido como outra forma de resolução do trauma, dessa vez saindo do simbólico e lidando diretamente com o real (Lacan, 2005b). Trata-se de um ato que carrega uma semântica com intuito de responder o desejo do Outro, uma natureza de súplica a esse desejo, uma demanda de atenção e de simbolização, uma resposta possível à angústia do momento. Miller (2016) nos ensina que o sujeito se põe a agir nessa cena diante do Outro, o espectador, um material recalcado para que este o dote de sentido e o valide. Constitui-se, assim, uma modalidade alienada da relação com o próprio desejo, a qual convoca o Outro para que lhe seja elucidado sobre o seu próprio desejo. Nesses trechos, vemos como o diário apresenta uma profusão de relatos nesse sentido: o sujeito perante um vírus mortal pode buscar elaborar seu trauma desde que a inscrição não atrapalhe sua produção, momentos de baixo investimento não são bem-aceitos.

No entanto, é importante destacar que há um índice de indeterminação sobre o sentido de tal produtividade nos testemunhos. Tal noção trata-se não somente de uma produção massificada no sentido fordista do termo, mas também de uma singularidade que persiste, que insiste em convocar o sujeito naquilo que o seu desejo busca produzir. Dessa multiplicidade de produtividades, podemos extrair o que Dunker (2015) chama de "experiências produtivas de indeterminação", ou seja, um hiato entre os significantes impostos pelo Outro, em que o sujeito tem um espaço para interpelar seu próprio desejo.

Ao evidenciar o ponto de ruptura do simbólico, o encontro com o real do vírus pode favorecer tais experiências de indeterminação, expondo a insuficiência dos significantes mestres que aparentemente regiam um único mundo possível, abrindo espaço para o questionamento de diversos estatutos como o do capitalismo neoliberal, indagação bastante presente nos debates atuais sobre a pandemia. Latour (2020) argumenta que a covid-19 jogou por terra a falácia da impossibilidade de suspender a produção capitalista e, assim, propõe atos que interditem a volta ao modelo pré-pandêmico e proponham novos sistemas mais comunitários e cooperativos. Na mesma linha, Zizek (2020) reflete sobre ser possível pensar modos de produções que forjem laços sociais ao invés de fragilizá-los, como faz o capitalismo neoliberal.

Não se pretende aqui ignorar o contexto socioeconômico nesta observação teórico-clínica e tampouco desconsiderar a realidade de muitos em que abdicar de trabalhar pode gerar um estado profundo de miséria, ao contrário, propomos uma reflexão radical sobre essa modalidade de existência, quer dizer, de produção, tida como única possível. Esforçar-se para sustentar inalterado o atual modo de produção como se não houvesse alternativas, é o negacionismo mais ingênuo e, por isso mesmo, o mais perigoso. É escolher se alienar perante a situação em que nos encontramos, é optar pelo fantasma da normalidade como se uma mudança do sistema de produção fosse uma anomalia sem precedentes e não o mais ordinário dos fenômenos históricos como já previsto por Marx.

Em nossa sociedade maníaca (Kehl, 2015), parece nos escapar cada vez mais o paradoxo de uma improdutividade produtiva, isto é, a possibilidade de uma produção singular, não massificada, única, sem valor de capital, ou ainda não produzir em absoluto e nos autorizarmos momentos de baixo investimento libidinal e de reorganização de afetos. A parada forçada pela pandemia seria uma contingência favorável à (im) produção e à (in)determinação, as quais, articuladas, poderiam gerar novos significantes para o sujeito, contudo, a sociedade maníaca e seu decorrente imperativo superegoico continuam a operar mesmo que remotamente, e nela o gozo permanece em produzir para o Outro. Assim, uma oportunidade de afrouxamento superegoico e de desalienação perante o discurso econômico do Outro é desperdiçada.

\section{(Im)possibilidades do Iuto: transformações da nossa atitude diante da morte}

Aquilo que desorienta os sujeitos em nossos tempos, para além do distanciamento social e da pandemia de covid-19, mantém uma relação estreita com o fracasso dos processos de simbolização, 
a potencialização do desamparo efetuada por algumas figuras presentes no Estado e com o imperativo superegoico da produção. Podemos acrescentar uma última perspectiva em nossa análise. 0 último elemento que exploramos em nossa análise e que parece estar presente no sofrimento e no sentimento de desorientação vivenciado atualmente é, como sugerido por Freud (2009), a perturbação da nossa atitude de distanciamento até então cotidiana perante a morte: Me sinto tão nova para estar presa nessa situação. Sinto que preciso crescer a cada dia para acompanhar o que está por vir. Fico pensando nas pessoas que nunca foram confrontadas com a morte, e como serão as semanas seguintes, porque acredito que muita gente vai morrer; Muita gente querida. (...) Parece que estou vivendo dentro de um parêntese. Devemos nos perguntar o que essa proximidade cotidiana com a morte pode produzir?

Freud, em seus Escritos sobre Guerra $e$ Morte (2009), nota que, quanto mais silenciamos ou nos distanciamos das verdades que surgem de nossos processos melancólicos e de luto frente à morte, quanto mais nutrimos nossa ilusão diante da morte, mais produzimos sintomas neuróticos que nos impedem de suportar a vida. Questiona, então, se não seria melhor atribuir à morte, na realidade e nos nossos pensamentos, o lugar que lhe compete e deixar vir um pouco mais à superfície a nossa atitude inconsciente diante da morte, que até agora tão cuidadosamente reprimimos. Em vez de silenciar, não deveríamos reconhecer o que de fato nos amedronta? É nesse sentido que recorre a famosa frase: "Se queres suportar a vida, preparate para a morte" (Freud, 2009, p. 31).

Um testemunho do blog aponta para isso: Eu reflito e constato... ofoco éum idoso. Considerado, porvezes, frágil, incapaz, desmiolado, transgressor, desatualizado, incompetente; suscetível à doença e ao risco de morte; impedido da socialização, destituído da autonomia e do lugar de sujeito nas suas escolhas, ações e responsabilidades. $\varepsilon$, de alguma forma, esse idoso se revela em mim nesse tempo de pandemia. Após um processo de reflexão extremamente aguçado, a autora (idosa) percebe que há um discurso que habita seus pensamentos, em que se vê pensando no "idoso" como algo externo, afastado, que não lhe diz respeito, mas quando se implica, olha mais de perto, se encontra, ela mesma corre riscos, e isso lhe causa surpresa: a surpresa de estar alienada de si. A fala revela a condição real da morte que nos escapa constantemente: "no fundo ninguém crê em sua própria morte [...] no inconsciente cada um de nós está convencido de sua própria imortalidade" (Freud, 2009, p. 19).

Dada essa dificuldade em aceitar a mortalidade, Leite (2019) insiste na importância da demarcação simbólica da morte, relegá-la à dimensão do real pode impedir um devido processo de luto, ou seja, a retomada e o reinvestimento libidinal em outro objeto. A morte biológica, como pertencente ao registro do real, nunca é suficiente, ela apenas existe quando devidamente demarcada pelo simbólico. É imediata a lembrança dos parentes de vítimas da covid-19 que são impedidos de ver os corpos de seus familiares devido a restrições sanitárias. O que esconde aquele caixão selado? Haveria de fato o ente querido morto ali dentro? A pandemia nos transforma todos em Antígonas sem podermos enterrar devidamente nossos entes queridos.

O luto demanda tempo, uma (re)alocação das representações simbólicas, uma queda de identificações, uma simbolização daquilo que se foi, uma aceitação da perda e, como resultado desse processo, uma transformação de si. Impossibilitar o luto, portanto, encaminharia o sujeito a um processo de melancolização, de fixação ao objeto perdido, seria criar um obstáculo do processo transformativo que o enfrentamento da morte pode potencializar, afinal, deveríamos ser capazes nesses momentos de "nos confrontar com o caos, confrontarse com o que aparece a um certo conceito de razão como abismo, e sentir-se bem. Pois esse sentimento nasce da certeza de que não devemos ter medo de ir onde não encontramos mais as luzes projetadas por nossa própria imagem” (Safatle, 2012, contracapa).

\section{Considerações finais}

Retomar as produções enunciativas dos sujeitos que vivenciam a pandemia, com suas significações, polissemias e manifestações do inconsciente, nos mostrou que existe um saber transformador que busca se fazer reconhecer por esses sujeitos. As possibilidades desse saber transformativo 
comparecem, nos testemunhos, como vimos, nos sonhos de angústia, em que notamos surgir a possibilidade do encontro com uma verdade dolorida, porém necessária, uma necessidade do sujeito de se permitir ir além das suas demandas de amparo. Comparece em seus afetos, como o medo potencializado por figuras do Estado, que a partir dele criam demandas por cuidado ou autoridade. Comparece, em sua perda da capacidade laborativa, na busca automática pelo restabelecimento de uma rotina, mas também no potencial criativo de uma improdutividade produtiva, que ensaia uma abertura para além do imperativo de produção capitalista. Comparece, por último, no encontro angustiante, porém potencialmente transformador, com a morte, que poderia vir a permitir os sujeitos se despossuírem das antigas individualidades que os faziam sofrer de maneira repetitiva e estereotipada. Observamos, no entanto, os limites da escrita de testemunhos no blog virtual, pois as postagens nos diários em certos momentos se tornavam "desabafos" protocolares sobre o dia a dia, e a pouca interação entre os alunos dificultava a elaboração por meio de uma dimensão coletiva.

O desamparo é entendido para a psicanálise como constitutivo da condição humana. A questão que devemos nos colocar é como o sujeito vive o seu desamparo, e quais respostas privilegiadas o Estado fornece para isso, seus efeitos subjetivos e consequências políticas. É lugar comum pensar que os afetos do desamparo e as situações traumáticas geram sofrimento em si mesmos, que são perigosos e devem ser evitados a todo custo. O Estado, o saber médico, a psicoterapia e outros discursos surgem, então, como dispositivos que buscam atender a essas demandas por cuidado, contudo, pensamos que cuidado não se emparelha forçosamente com amparo, ou num fazercessar da angústia. Pensamos e buscamos demonstrar aqui que há potências transformativas também no desamparo e na indeterminação.

O que nossas reflexões puderam extrair da narrativa dos sujeitos que vivenciam os tempos de encontro com o real da pandemia é que, nos confins do confinamento, vemos o potencial transformador que se anuncia na vivência do afeto do desamparo. Sujeitos que em seus testemunhos gritam (como no despertar de um pesadelo), que estão se deparando com uma verdade que os atravessa e que pode lhes transformar em um nível desesperador por ser desconhecido. Grito que não busca dizer “socorro”, o que instituiria novas relações de dependência, que aprisionariam o sujeito em uma temporalidade da espera, para que ele voltasse passivamente a ser quem era antes, mas busca dizer “chega!", exigir algo, na temporalidade do ato, e encaminhá-lo para uma saída independente, em que se possa exercer a singularidade daquilo que o Eu desconhece.

Sem negarmos as legítimas demandas de amparo dirigidas ao Outro, argumentamos em prol da necessidade de rearticular tal demanda por meio da dimensão social do sofrimento particular, pensamos que, a partir do momento que pudermos reconhecer o valor transformador das experiências do desamparo, talvez possamos recolher nos testemunhos dos tempos de pandemia todo seu potencial analítico e político.

\section{Referências}

ABRÃO, P. Prefácio. In: SIGMUND FREUD ASSOSCIAÇÃO PSICANALÍTICA. Clínicas do testemunho: reparação psíquica e construção de memórias. Porto Alegre: Criação Humana, 2014. p. 9-22.

\section{APPOA - ASSOCIAÇÃO PSICANALÍTICA} DE PORTO ALEGRE. Por que uma clínica do testemunho? Porto Alegre: 2018.

BARDIN, L. Análise de conteúdo. Lisboa:

Edições 70, 1977.

BETTS, J. Trauma e testemunho. In: APPOA. Por que uma clínica do testemunho? Porto Alegre: 2018. p. 113-127.

DUNKER, C. I. L. Mal-estar, sofrimento e sintoma: uma psicopatologia do Brasil entre muros.

São Paulo: Boitempo, 2015.

FREUD, S. Projeto para uma psicologia científica. In: FREUD, S. Edição standard brasileira das obras psicológicas completas de Sigmund Freud. Rio de Janeiro: Imago, 199o. p. 385-529. v. 1.

FREUD, S. As neuropsicoses de defesa. In: FREUD, S. Edição standard brasileira das obras psicológicas completas de Sigmund Freud. Rio de Janeiro: Imago, 1996a. p. 25-39. v. 3. 
FREUD, S. Além do princípio do prazer. In: FREUD, S. Edição standard brasileira das obras psicológicas completas de Sigmund Freud. Rio de Janeiro: Imago, 1996b. p. 3-42. v. 18.

FREUD, S. Escritos sobre a guerra e a morte. Covilhã: Universidade da Beira Interior, 2009.

KEHL, M. R. O tempo e o cão: a atualidade das depressões. Boitempo Editorial, 2015.

LACAN, J. O seminário livro 17: o avesso da psicanálise. Rio de Janeiro: Zahar, 1992.

LACAN, J. O triunfo de religião: precedido de discurso aos católicos. Rio de Janeiro: Zahar, 2005a.

LACAN, J. O seminário livro 1o: a angústia.

Rio de Janeiro: Zahar, 2005b.

LACAN, J. O seminário livro 21: os não-tolos erram. Recife: Traço Freudiano, 2018.

LATOUR, B. Imaginar gestos que barrem o retorno da produção pré-crise. São Paulo: N-1 Edições, 2020.

LEITE, S. O inominável e a transitoriedade. Revista Latinoamericana de Psicopatologia Fundamental, São Paulo, v. 22, n. 1, p. 11-19, 2019. DOI: 10.1590/1415-4714.2018v22n1p11.1
LEVI, P. É isto um homem? Rio de Janeiro: Rocco, 1988.

LUSTOZA, R. Z. O discurso capitalista de Marx a Lacan: algumas consequências para o laço social. Ágora: Estudos em Teoria Psicanalítica, Rio de Janeiro, v. 12, n. 1, p. 41-52, 2009.

DOI: 10.1590/S1516-14982009000100003

MILLER, J.-A. Perspectivas do Seminário 23 de Lacan: o sinthoma. Rio de Janeiro: Zahar, 2016.

QUINET, A. A ciência psiquiátrica nos discursos da contemporaneidade. In: QUINET, A. et al. (org.). Psicanálise, capitalismo e cotidiano. Goiânia: Edições Germinal, 2002. p. 32-38.

RAMOS, L. N. Prefácio. In: APPOA. Por que uma clínica do testemunho? Porto Alegre: 2018. p. 11-17.

SAFATLE, V. Grande Hotel Abismo: por uma reconstrução da Teoria do Reconhecimento. São Paulo: Editora WMF Martins Fontes, 2012.

SAFATLE, V. O circuito dos afetos: corpos políticos, desamparo e o fim do indivíduo. São Paulo: Autêntica, 2016.

ZIZEK, S. Pandemia: Covid-19 e a reinvenção do comunismo. São Paulo: Boitempo, 2020.

\section{Contribuição dos autores}

Souza Junior foi responsável pela organização da pesquisa, coleta de dados, processamento de dados, redação, revisão e submissão. Henderson foi responsável pela organização da pesquisa, coleta de dados, processamento de dados, redação, revisão e submissão.

Recebido: $30 / 05 / 2020$

Aprovado: 06/01/2021 